\title{
Conselhos de Alimentação Escolar em Santa Catarina, Brasil: uma análise do Discurso do Sujeito Coletivo
}

\author{
School Nutrition Councils in Santa
}

Catarina, Brazil: Collective

Subject Discourse analysis

Patrícia Maria de Oliveira MACHADO ${ }^{1}$

Bethsáida de Abreu Soares SCHMITZ2

Arlete Catarina Tittoni CORSO ${ }^{1,3}$

Gilberto Veras CALDEIRA ${ }^{3}$

Francisco de Assis Guedes de VASCONCELOS ${ }^{1,3,4}$

\section{R E S U M O}

\section{Objetivo}

Identificar no discurso dos conselheiros de alimentação escolar a compreensão sobre as funções, os limites e os avanços da atuação dos Conselhos de Alimentação Escolar.

\section{Métodos}

Trata-se de um estudo qualitativo que utilizou entrevistas com roteiro semiestruturado baseadas na técnica de Grupos Focais em nove Conselhos de Alimentação Escolar do estado de Santa Catarina, sendo oito conselhos municipais e um estadual. As falas dos conselheiros foram gravadas, posteriormente transcritas e analisadas a partir do método do Discurso do Sujeito Coletivo.

\section{Resultados}

Foram construídos cinco discursos, agrupados segundo as ideias centrais emergentes. Destacam-se os avanços conquistados pela atuação dos Conselhos de Alimentação Escolar e a capacidade limitada de intervenção na

${ }^{1}$ Universidade Federal de Santa Catarina, Centro de Ciências da Saúde, Programa de Pós-Graduação em Nutrição. Florianópolis, SC, Brasil.

${ }^{2}$ Universidade de Brasília, Departamento de Nutrição. Brasília, DF, Brasil.

3 Universidade Federal de Santa Catarina, Centro de Ciências da Saúde, Departamento de Nutrição. Florianópolis, SC, Brasil.

${ }^{4}$ Universidade Federal de Santa Catarina, Centro Colaborador de Alimentação e Nutrição do Escolar do Estado de Santa Catarina, Departamento de Nutrição. Campus Universitário, Sala 215, Caixa Postal 476, Trindade, 88040-900, Florianópolis, SC, Brasil. Correspondência para/Correspondence to: FAG VASCONCELOS. E-mail: <f.vasconcelos@ufsc.br>.

Apoio: Fundo Nacional de Desenvolvimento da Educação (Termo de Cooperação no 429/2008), para a execução do produto "Avaliação dos conselhos municipais e estadual de Santa Catarina", parte do Plano de Trabalho (2008-2009) do Centro Colaborador da Universidade Federal de Santa Catarina. 
gestão da alimentação escolar. Os achados corroboram a literatura no que se refere ao excesso de burocracia para atuação dos conselhos, à compreensão dos conselheiros sobre os espaços democráticos institucionalizados como de controle social e à falta de comprometimento e representatividade dos membros envolvidos.

\section{Conclusão}

Entre os temas analisados, ressaltam-se a compreensão do papel de fiscalização do Conselho de Alimentação Escolar, o conceito de controle social que envolve a participação no Programa Nacional de Alimentação Escolar, e a compreensão desse programa como uma política de Segurança Alimentar e Nutricional. Verifica-se a necessidade de continuidade da formação e qualificação de conselheiros e de estímulo à participação democrática que vise a uma maior representação social. Dessa forma, contribui-se para o resgate da capacidade dos conselhos de intervirem na execução da política pública.

Palavras-chave: Alimentação escolar. Participação social. Pesquisa qualitativa.

\section{A B S T R A C T}

\section{Objective}

Identify in the committee members' discourse the understanding of the School Nutrition Councils' functions and the actions taken by their members.

\section{Methods}

This is a qualitative study, and data were collected using a questionnaire with semi-structured interviews based on the Focus Groups technique in School Nutrition Councils' in the state of Santa Catarina. A total of nine councils were analyzed (eight municipal councils and one state council). The council members' discourse was recorded, transcribed, and analyzed according to the Collective Subject Discourse method.

\section{Results}

Five Collective Subject Discourses' were built and grouped according to the Central Ideas. The advances made by the actions of the School Nutrition Councils' members and their limited ability to intervene in the school nutrition management were observed. The findings corroborate those in the literature with regard to: excessive bureaucracy hindering or preventing council member actions, the understanding the councilors of democratic institutionalized spaces such as social control, and the lack of commitment and representativeness of the members involved.

\section{Conclusion}

Among the topics analyzed, the following should be highlighted: the understanding the role of the School Nutrition Councils in supervising activities; the social control concept, which involves participation in the National School Nutrition Program; and the understanding of this program as a Food and Nutrition Security policy. There is a need for further training and of councilors and the encouragement of democratic participation aiming at greater social representation thus contributing to improve their ability to intervene in the implementation of public policies.

Keywords: School food. Social participation. Qualitative research.

\section{N T R O D U Ç Ã O}

O processo de redemocratização no Brasil, que culminou com a aprovação da Constituição Federal de 1988, instituiu a participação da sociedade civil na gestão das políticas públicas em todas as esferas de governo ${ }^{1}$. Com a criação de conselhos setoriais de participação democrática, deu-se abertura ao controle social e à maior transparência na utilização de recursos públicos, além de possibilitar a indicação de ações propositivas para a execução das políticas públicas ${ }^{2,3}$.

A participação democrática na gestão governamental denomina-se controle social, sendo este entendido como um espaço de representação da sociedade que promove a articulação de diferentes grupos populares. De um lado, situam-se os representantes das entidades de classe, do 
governo e dos prestadores de serviço, e, de outro, a população com suas necessidades e interesses. O controle social consiste, portanto, em portas institucionais de participação na gestão pública, com a presença de sujeitos coletivos nos processos decisórios ${ }^{4}$.

No Brasil, a participação democrática com a existência de espaços de controle social ainda é frágil, uma vez que a maioria dos cidadãos desconhece sua existência, ou, ainda, as administrações governamentais controlam tais espaços com representações próximas do governo. Isso garante a presença de indicações políticas, muitas vezes como tentativa de manter a continuidade na transferência de recursos da União, já que a população e outras entidades não ocupam os devidos espaços ${ }^{5-7}$.

O controle social no contexto do Programa Nacional de Alimentação Escolar (PNAE) tornou-se realidade no Brasil a partir de 1994, quando começou a ocorrer a transferência/descentralização de recursos financeiros do governo federal aos estados e municípios. Assim, fez-se necessária a criação dos conselhos locais para a fiscalização da execução do PNAE em nível local, denominados de Conselhos de Alimentação Escolar $(C A E)^{8-10}$.

Ao constituir-se em importante instância para o controle social do PNAE, o CAE deve, entre suas atribuições, fiscalizar e acompanhar a exeCução do PNAE, zelar pela qualidade sanitária e aceitabilidade dos alimentos, elaborar parecer conclusivo sobre a prestação de contas, entre outras competências ${ }^{11-13}$.

A literatura aponta que os conselhos foram essenciais no processo de mudança no escopo das políticas públicas de alimentação e nutrição no Brasil, e impulsionaram, na última década, a inclusão das temáticas Segurança Alimentar e Nutricional (SAN) e Direito Humano à Alimentação Adequada (DHAA) nas políticas públicas dessa área, sobretudo no PNAE ${ }^{14,15}$. Dessa forma, a capacitação de conselheiros dos CAE tem sido um dos focos de atuação dos Centros Colaboradores em Alimentação e Nutrição do Escolar (Cecane), criados a partir de 2006, por meio de parceria entre Universidades Federais e o Fundo Nacional de Desenvolvimento da Educação (FNDE).

Atualmente, as atribuições, as competências e a composição do CAE estão definidas na Lei $n^{\circ} 11.947$, de 16 de junho de 2009, que determina a criação de conselhos nos estados, municípios e Distrito Federal como órgãos colegiados que atuam em caráter fiscalizador, permanente, deliberativo e de assessoramento, compostos por um representante do poder executivo, dois representantes de entidades de trabalhadores da educação e de discentes, dois representantes de pais de alunos e dois representantes de entidades civis organizadas ${ }^{11}$.

A partir de 2009, com as importantes alterações sofridas pelo PNAE, oriundas da chamada "Lei da Alimentação Escolar" (Lei n 11.947/ 2009)11 e de outros instrumentos legais complementares que a sucederam ${ }^{12,13}$, é notável o número de artigos publicados sobre a temática nos periódicos nacionais que compõem a base Scientific

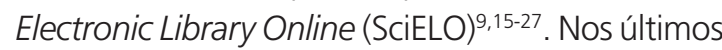
cinco anos, embora se identifique interesse emergente pela temática alimentação escolar, consideram-se ainda escassos os estudos sobre a atuação dos CAE no Brasil. Mais escassos ainda são os estudos com abordagens qualitativas sobre a atuação de tais conselhos. Nessa perspectiva, diante do relevante papel dos CAE na eficiência e eficácia do PNAE e, por consequência, na garantia do direito à alimentação escolar saudável, adequada e sustentável para todos os escolares brasileiros, justifica-se a realização da abordagem qualitativa utilizada na investigação que gerou o presente artigo.

O objetivo central do artigo foi identificar no discurso dos conselheiros de alimentação escolar a compreensão sobre as funções, os limites e os avanços da atuação dos CAE no estado de Santa Catarina.

\section{MÉ TODOS}

Este estudo fez parte de pesquisa realizada pelo Cecane de Santa Catarina com o objetivo 
de investigar a atuação dos CAE nesse estado. A pesquisa foi realizada no período de maio de 2008 a fevereiro de 2009, sendo composta por duas etapas: uma quantitativa que incluiu uma amostra representativa ( $n=153$ ) dos 293 municípios catarinenses ${ }^{16}$ e outra qualitativa, a qual é o enfoque deste artigo.

A abordagem qualitativa, de acordo com Minayo 28,29 , tem se preocupado em responder temáticas mais complexas, uma vez que possui um nível de profundidade maior na análise de fatos e representações da sociedade ${ }^{28}$. Os dados qualitativos representam o modo de agir e pensar no viver social dos sujeitos entrevistados ${ }^{29}$.

O projeto de pesquisa foi aprovado pelo Comitê de Ética em Pesquisa com Seres Humanos da Universidade Federal de Santa Catarina (UFSC), sob o parecer $n^{\circ}$ 024/2008.

Para a definição do número de CAE participantes, foram utilizados como critérios os municípios com o maior número de matrículas no Ensino Fundamental do Estado de Santa Catarina de acordo com o Censo Escolar de 2007. Além disso, o CAE, no momento da pesquisa, deveria ter gestão superior a seis meses, e os municípios deveriam ter participado da parte quantitativa da pesquisa. Mediante esse critério de inclusão, foram selecionados oito municípios catarinenses: Araranguá, Brusque, Criciúma, Florianópolis, Lages, Palhoça, São José e Tubarão, além do CAE estadual, que funcionava em Florianópolis.

A pesquisa de campo foi realizada nos próprios municípios. A visita dos entrevistadores foi previamente agendada por telefone, sendo solicitado que no dia agendado houvesse no município uma sala de reuniões reservada e que fossem convidados todos os conselheiros do CAE para participação da investigação. Para a coleta das informações, foi realizada a metodologia de grupo focal com cada CAE investigado. Neste estudo, o grupo focal foi concebido como uma técnica de coleta de dados qualitativos, obtidos diretamente das falas dos membros do grupo sobre suas percepções e experiências a respeito de um tema específico ${ }^{30,31}$.
Foi utilizado um roteiro semiestruturado aplicado por dois entrevistadores que tinham graduação em Nutrição e experiência na área de alimentação escolar. Eles tiveram papéis definidos previamente, um de coordenador do grupo e outro de observador. O roteiro semiestruturado apresentava perguntas norteadoras baseadas nas temáticas: 1) compreensão do conselho sobre alimentação escolar; 2) controle social na alimentação escolar; 3) atribuições do CAE; e 4) limites e avanços de atuação do conselho. Todo o processo de grupo focal foi gravado e posteriormente transcrito para a análise de dados, sendo a transcrição dos dados realizada por empresa contratada e posteriormente conferida sistematicamente pelos pesquisadores.

O método do Discurso do Sujeito Coletivo (DSC), baseado em Lefréve \& Lefréve ${ }^{32-34}$, foi a técnica utilizada para a análise das falas obtidas nos Grupos Focais (GF). Esse método constitui uma possibilidade de expressar, de forma empírica, a opinião ou o pensamento de determinada coletividade $^{32}$. O processo de construção do DSC é definido por uma série de operações com os diferentes depoimentos coletados, que, ao final, produzem um único discurso em primeira pessoa do singular com o efeito de uma opinião coletiva $^{33}$.

A análise dos dados foi feita manualmente, sem a utilização de software específico. A sequência dos procedimentos será descrita a seguir. Para a construção dos DSC, foram utilizados quatro operadores propostos por Lefréve

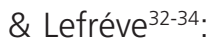

1. Expressões-Chave (ECH): correspondem aos trechos selecionados (grifados) de cada um dos depoimentos, que se caracterizam por melhor expressar o conteúdo da fala;

2. Ideias Centrais (IC): são formulações de frases que descrevem sinteticamente os sentidos dos depoimentos;

3. Categorias: São expressões sintéticas que agrupam as ideias centrais de sentidos semelhantes ${ }^{34}$; 
4. Discurso do Sujeito Coletivo são reuniões das Expressões-Chave de uma mesma Categoria de Ideia Central ou Ancoragem.

Assim, foram construídos os discursos-síntese (DSC), na primeira pessoa do singular. Esses procedimentos podem ser visualizados nos Quadros 1 e 2, que contam com o exemplo da construção de um dos discursos.

Os Discurso do Sujeito Coletivo construídos por meio das falas dos conselheiros entrevistados foram organizados segundo as temáticas do roteiro e IC emergentes da análise (Quadro 3). Para preservar o anonimato dos sujeitos, suas falas foram codificadas sequencialmente conforme a ordem de realização dos grupos, momento da fala e local de realização. [Exemplo: $S=S u j e i t o ; ~ 6=6^{a}$ fala do grupo; Ig=município de Lages (Código: S.6lg)].

\section{RESULTADOS E DISCUSSÃO}

Foram realizados nove grupos focais, sendo oito compostos por representantes dos conselhos de alimentação escolar dos municípios previamente selecionados e um pelos membros

Quadro 1. Exemplo da construção das expressões-chave e ideias centrais a partir das falas dos grupos focais. Método do Discurso do Sujeito Coletivo. Florianópolis, 2008-2009.

\begin{tabular}{|c|c|c|}
\hline \multicolumn{3}{|c|}{ QUAIS OS AVANÇOS CONQUISTADOS PELO CONSELHO DE ALIMENTAÇÃO ESCOLAR? } \\
\hline Sujeito & Expressão Chave & Ideia Central \\
\hline S.2CR & $\begin{array}{l}\text { Primeiro a autonomia do conselho (...) para trabalhar, para visitar, conhecer, cobrar. Se- } \\
\text { gundo é o comprometimento das pessoas que estão aqui. Participar dos processos de } \\
\text { licitação, conhecer os fornecedores, o preço de cada alimento, se não há desvio. }\end{array}$ & \\
\hline S.4CR & $\begin{array}{l}\text { Nas escolas tinha muita coisa errada, então hoje a gente tava vendo, veio o pessoal de } \\
\text { Brasília (...) agora os depósitos e as cozinhas estão 100\%, está melhorando cada vez } \\
\text { mais. }\end{array}$ & $\begin{array}{l}\text { Autonomia e eleição demo- } \\
\text { crática do conselho, alimen- } \\
\text { tação escolar melhorando } \\
\text { no município. }\end{array}$ \\
\hline S.2FL & $\begin{array}{l}\text { Um dos avanços, como a gente falava antes, é a questão da divulgação. Realmente o } \\
\text { conselho a partir desse mandato, saiu de dentro dos portões da secretaria (...) represen- } \\
\text { tantes de pais eram funcionários também do órgão central (...) e este nosso conselho, } \\
\text { nós fomos realmente eleitos e isso foi um grande avanço. }\end{array}$ & \\
\hline
\end{tabular}

Nota: S.2CR: Sujeito2 Criciúma; S.4CR: Sujeito4 Criciúma; S.2FL: Sujeito2 Florianópolis.

Quadro 2. Exemplo de construção do Discurso do Sujeito Coletivo (DSC) a partir das ideias centrais e expressões-chave. Método do DSC. Florianópolis, 2008-2009.

\begin{tabular}{|c|c|c|}
\hline \multicolumn{3}{|c|}{ QUAIS OS AVANÇOS CONQUISTADOS PELO CONSELHO DE ALIMENTAÇÃO ESCOLAR? } \\
\hline Ideia Central & Expressão Chave & Discurso do Sujeito Coletivo \\
\hline $\begin{array}{l}\text { Autonomia e eleição } \\
\text { democrática do con- } \\
\text { selho, alimentação } \\
\text { escolar melhorando } \\
\text { no município }\end{array}$ & $\begin{array}{l}\text { Primeiro a autonomia do conselho (...) para trabalhar, para visitar, co- } \\
\text { nhecer, cobrar. Segundo é o comprometimento das pessoas que estão } \\
\text { aqui. Participar dos processos de licitação, conhecer os fornecedores, } \\
\text { o preço de cada alimento, se não há desvio. } \\
\text { Nas escolas tinha muita coisa errada, então hoje a gente tava vendo, } \\
\text { veio o pessoal de Braślia (...) agora os depósitos e as cozinhas estão } \\
100 \% \text {, está melhorando cada vez mais. } \\
\text { Um dos avanços, como a gente falava antes, é a questão da divulga- } \\
\text { ção. Realmente o conselho a partir desse mandato, saiu de dentro dos } \\
\text { portões da secretaria (...) representantes de pais eram funcionários tam- } \\
\text { bém do órgão central (...) e este nosso conselho, nós fomos realmente } \\
\text { eleitos e isso foi um grande avanço. }\end{array}$ & $\begin{array}{l}\text { Autonomia do conselho para traba- } \\
\text { Ihar, visitar, cobrar, participar das lici- } \\
\text { tações, conhecer fornecedores, ver se } \\
\text { não há desvio. Também há o compro- } \\
\text { metimento das pessoas que estão } \\
\text { aqui, já que nós fomos realmente elei- } \\
\text { tos e isso foi um grande avanço. Nas } \\
\text { escolas havia muita coisa errada, ago- } \\
\text { ra está melhorando cada vez mais. E } \\
\text { por fim, tem a questão da divulgação, } \\
\text { já que o Conselho de Alimentação Es- } \\
\text { colar (CAE) saiu de dentro dos portões } \\
\text { das secretaria. }\end{array}$ \\
\hline
\end{tabular}


Quadro 3. Categorias de Análise e Ideias Centrais (IC) emergentes conforme as temáticas e conteúdos das falas analisadas por meio do método de Discurso do Sujeito Coletivo (DSC). Florianópolis, 2008-2009.

\begin{tabular}{lr}
\hline Categorias & \multicolumn{1}{c}{ Ideias Centrais } \\
\hline $\begin{array}{l}\text { Função do Conselho de Alimentação } \\
\text { Escolar (CAE) }\end{array}$ & $\begin{array}{l}\text { IC 1. Fiscalizar e acompanhar a execução do Programa Nacional de Alimentação Escolar } \\
\text { (PNAE) em todas as etapas. }\end{array}$ \\
$\begin{array}{l}\text { Definindo Controle Social } \\
\text { IC 2. Controle Social é a sociedade participando da execução do PNAE, mas ainda precisa } \\
\text { avançar. }\end{array}$ \\
$\begin{array}{l}\text { Limites e Avanços para a atuação do } \\
\text { CAE }\end{array}$ & $\begin{array}{l}\text { IC } 3 \text {. Falta de comprometimento dos membros, falta de autonomia, verbas e transporte } \\
\text { município. }\end{array}$ \\
$\begin{array}{l}\text { A visão do programa de alimentação } \\
\text { escolar como uma política pública de } \\
\text { Segurança Alimentar e Nutricional } \\
\text { (SAN) }\end{array}$ & $\begin{aligned} \text { IC } 5 \text {. O Direito Humano à Alimentação Adequada (DHAA) está inserido na legislação e em } \\
\text { todas as diretrizes do PNAE, e necessita ser consolidado, mas não apenas no programa. }\end{aligned}$ \\
\hline
\end{tabular}

do CAE estadual. Todos os CAE contatados aceitaram a participação. A gravação das seções dos grupos focais resultou em 120 páginas de transcrição das falas dos conselheiros entrevistados, as quais foram analisadas conforme o método do DSC $32-34$.

Os resultados dos procedimentos de análise serão apresentados e discutidos na sequência em quatro seções, a saber: 1) Função do Conselho de Alimentação Escolar; 2) Definindo Controle Social; 3) Limites e Avanços na atuação do CAE; e 4) A visão do PNAE como uma política pública de Segurança Alimentar e Nutricional.

\section{Função do Conselho de Alimentação Escolar}

O processo de reconhecimento das funções do CAE no conjunto das falas dos conselheiros entrevistados foi agrupado na Ideia Central 1 (IC1): "Fiscalizar e acompanhar a execução do Programa Nacional de Alimentação Escolar em todas as etapas". O DSC da IC1 foi enunciado da seguinte forma:

Garantir a qualidade da alimentação escolar através da fiscalização de todos os processos de preparo e distribuição dos alimentos, se está tudo limpo (...) ver a prestação de contas, fazer reuniões e visitas. Além disso, o conselho deve verificar a aceitabilidade da alimentação na escola e atender denúncias (S.6es; S.1es; S.3es; S.5es; S.1pç; S.2pç; S.2sj; S.1sj; S.2fl; S.6fl; S.6bq; S.2lg).

No que se refere às funções do conselho, observa-se a tendência de atribuir ao CAE um caráter fiscalizatório dos aspectos de qualidade e higiene, além da prestação de contas e aceitabilidade. Os aspectos higiênicos e sanitários na produção de refeições, sobretudo na alimentação escolar, traduzem-se em um aspecto fundamental ${ }^{24}$, porém a capacidade de modificar a execução da política pública, função efetiva de controle social, ou seja, da sociedade civil empoderada ${ }^{35}$, não é percebida pelos conselheiros.

Estudo qualitativo com conselheiros do CAE de um município catarinense também identificou os aspectos higiênicos e sanitários como o principal aspecto de segurança alimentar e nutricional para a alimentação escolar, segundo os entrevistados ${ }^{25}$. As percepções de que atividades realizadas pelo CAE (tais como visitas e reuniões) são funções elementares, entretanto, sem identificação dos objetivos pelo quais se realizam tais atividades, também foram contempladas em outros estudos. Estudo com todos os conselhos existentes em uma secretaria municipal de educação, também utilizando grupos focais, identificou como principais funções dos conselhos a fiscalização e a sugestão de ações para a gestão ${ }^{5}$. Na área da saúde, estudo realizado com con- 
selheiros municipais apresentou conceitos diversos sobre a função do conselho, como a deliberação de decisões, a realização de reuniões e a fiscalização ${ }^{36}$.

Ressalta-se que no Discurso do Sujeito Coletivo dos CAE em Santa Catarina não se identificou a efetivação da atribuição de controle social como principal função do conselho, ou mesmo o reconhecimento desse espaço como órgão de participação social. Entretanto, assim como em outras políticas públicas, espera-se que o controle social na alimentação escolar deva ser pró-ativo, para além do caráter de fiscalização, visando proporcionar um espaço de construção coletiva e de diálogo e possibilitar a superação de desafios em prol da qualidade da alimentação ${ }^{37}$.

As atuais funções/atribuições do CAE estão estabelecidas em legislação específica ${ }^{11,13}$, destaca-se, porém, que, ao longo da história do PNAE, essas funções foram construídas/institucionalizadas socialmente, na medida em que os CAE se formaram a partir da descentralização administrativa e financeira do programa ${ }^{8-10}$. Dessa forma, conforme observado em estudo anterior, publicado em 200338, o procedimento de assinar, uma vez por ano, as prestações de contas da entidade executora do PNAE para o FNDE tornou-se o principal reconhecimento da função do CAE. No presente estudo, essa função do CAE também pode ser observada no fragmento do DSC, sintetizado na frase dos conselheiros entrevistados, que expressa a principal atribuição desses conselhos: "ver a prestação de contas".

Estudo de Kleba et al..$^{5}$ indica que a efetividade da atuação dos conselhos está condicionada por fatores como a capacidade de formulação de propostas de seus conselheiros, a capacidade de negociação de propostas com a gestão e a autonomia dos atores que os constituem. E acrescentam que quando tais fatores não ocorrem, "o que se constata é que foram desconcentradas responsabilidades e não democratizado o poder" (p.794) $)^{5}$.

No presente estudo, não foram citadas funções que englobassem a formulação e a ne- gociação de propostas pelos conselhos. Identificou-se que algumas atividades realizadas, citadas no discurso, como realizações de testes de aceitabilidade, caberiam à Entidade Executora $^{11,13}$, o que caracteriza a descentralização de responsabilidades.

De acordo com Pipitone et al. ${ }^{38}$, em pesquisa realizada com 1378 municípios brasileiros, nos primeiros anos de descentralização do PNAE, a maioria dos CAE participantes do estudo encontrava-se inoperante ou ainda criada apenas para atender a exigência da lei. Percebe-se, assim, o processo de evolução no discurso dos CAE investigados em Santa Catarina, que acrescentaram atividades realizadas que caracterizam um CAE mais atuante. Tal percepção indica a possibilidade da efetividade da atuação dos conselhos de alimentação escolar, ainda que a compreensão da função de intervir nas ações da gestão do PNAE não se faça presente nas falas dos conselheiros entrevistados. Essa perspectiva é reforçada pelas IC2 e IC3 extraídas das falas dos conselheiros investigados, as quais serão abordadas nas próximas seções do presente artigo.

\section{Definindo controle social}

Sobre a definição de controle social dos conselheiros entrevistados, reuniu-se a Ideia Central 2 (IC2): "Controle Social é a sociedade participando da execução do PNAE, mas ainda precisa avançar". O DSC da IC2 foi assim enunciado:

Como o conselho é formado por vários segmentos da sociedade, todos tem controle. Mas é a sociedade garantindo o controle e a execução do PNAE. O povo brasileiro ainda não trabalha pelo controle social. Precisa ser mais divulgado (S.2cr; S.3cr; S.1bq; S.3bq; S.ifl; S.4tb; S.2sj; S.2lg; S.1es; S.3es).

Nota-se que existe um consenso sobre a necessidade de avanços na efetivação da participação da sociedade, não só na alimentação escolar. Além disso, evidencia-se o controle social como a sociedade empoderada na execução do 
PNAE. De acordo com Gerschman ${ }^{35}$, em estudo qualitativo na área da saúde, a ideia de "controle social" foi diferente entre os conselheiros entrevistados: o termo era usado como a capacidade de a sociedade organizada intervir na gestão pública, orientando as ações e gastos do Estado em prol dos interesses da comunidade, ou ainda, como o controle que o Estado exercia sobre a sociedade.

Segundo Alvarez ${ }^{39}$, uma vez que o controle social é institucionalizado e burocratizado, tem-se a ideia de que ele existe para manter uma ordem social, ou obedecer às regras, quando os conselhos deveriam ter liberdade para propor novos rumos de uma política pública. Nesse processo, conforme apontam outros autores, o lado que se beneficia é a gestão, pois possui conselhos que agem apenas validando a ação do estado ${ }^{5,35}$.

Outro aspecto importante é o reconhecimento de que os diversos segmentos representados na composição do CAE não são atuantes no processo de decisão, o que dificulta o processo democrático e efetivação do controle social. Dessa forma, segundo Kleba et al. ${ }^{5}$, os conselhos deveriam "constituir-se de espaços de aprendizado da democracia, exercitando a formulação de consensos, uma vez que o que está em jogo é o interesse coletivo, que nem sempre coincide com o interesse de uma "maioria" presente ou ali representada" (p.796). Motta \& Alcadipani6, por sua vez, indicam que as necessidades individuais são encaradas como mais importantes no processo de vida do que as necessidades sociais ou de determinado conjunto social.

Em estudo qualitativo com conselhos municipais de saúde, foi observado que os representantes vinculados a espaços de atuação política como sindicatos possuíam vantagens em sua atuação no conselho em qualquer discussão, "em função da força de argumentação e da credibilidade que eles adquiriram perante os demais conselheiros" (p.53) ${ }^{40}$. Assim, existe a necessidade de formação continuada de conselheiros a fim de instigar o reconhecimento dos papéis dos ato- res sociais e principalmente de suas funções, tornando-se fundamental na efetivação do controle social a mediação das necessidades entre os representantes da gestão, da comunidade e dos professores presentes no CAE. Nesse sentido, o exercício do diálogo entre os diferentes representantes que compõem o conselho torna-se estratégia essencial na promoção da democracia participativa e se constitui o principal desafio para os conselheiros como interlocutores das entidades que representam ${ }^{5}$.

\section{Limites e avanços na atuação do CAE}

Entre as falas analisadas, encontraram-se expressões-chave que indicavam limitações na atuação dos conselhos. Nesse sentido, a IC3 foi resultante da aproximação dessas expressões: "Falta de comprometimento dos membros, falta de autonomia, verbas e transporte". O DSC derivado da IC3 foi assim enunciado:

Falta conhecimento dos conselheiros, então a gente vai na ideia de fazer alguma coisa de ajudar, daí as pessoas vêm na reunião e não sabem o que fazer e assinam aquilo já pronto, não sabe. Além disso, falta reconhecimento dos gestores, estrutura, como verba e transporte, e principalmente tempo, já que muitos conselheiros participam de outros conselhos (S.1pç; S.4pç; S.2pç; S.1es; S.2es; S.3es; S.6tb; S.1bq; S.8bq; S.2cr; S.2fl; S.6fl; S.ifl).

O Discurso do Sujeito Coletivo apontou como a principal dificuldade o desconhecimento por parte dos conselheiros sobre a parte burocrática que envolve as funções do CAE, cabendo muitas vezes aos representantes da gestão preparar os documentos necessários. Dessa forma, os demais membros, sem domínio adequado sobre esse processo, assinam documentos sem reconhecê-los. Outro ponto desse DSC indicou a existência de muitos conselhos existentes na secretaria de educação e os mesmos sujeitos serem repre- 
sentantes em diferentes conselhos, dificultando o trabalho do CAE. Somada a isso, há a falta de estrutura para reuniões, de verbas para projetos e de transporte para visitas e fiscalização das unidades escolares.

Kleba et al..$^{5}$ em sua investigação destacaram o desconhecimento dos conselheiros como a principal dificuldade para realizar ações pertinentes aos conselhos, porém tais ações de controle e fiscalização requerem competência técnica, como a definição de padrões de qualidade e a sugestão de melhorias na execução financeira dos programas, o que muitas vezes não é realizado.

Rodrigue $z^{41}$, por sua vez, ressalta que, em cidades menores, os conselhos apresentam um modo de atuar ambíguo em relação ao executivo municipal, e, geralmente, mesmo em municípios maiores, onde o grau de autonomia é mais preservado, o desconhecimento técnico dos representantes, os custos individuais da participação e os obstáculos colocados pela administração têm limitado a atuação dos conselheiros, o que corrobora o presente trabalho.

Em investigação sobre os conselhos locais de saúde, identificaram-se como limitações de atuação a burocratização da participação democrática, o entendimento de controle social restrito à participação, além da legitimidade das instituições da sociedade civil e suas representações $^{42}$.

É importante destacar que a efetividade do CAE apenas se dará quando essa instância de controle social orientar suas decisões pela participação da população de forma ampliada, com a presença de diferentes segmentos no processo de decisão, consolidando-se como uma instância fundamental para a gestão do PNAE, e não uma organização figurativa. Ainda assim, a transformação dos atores envolvidos no PNAE em cidadãos ativos, os quais opinam sobre o programa, controlam e fiscalizam-no por meio da valorização dos CAE, é um processo social a ser ainda consolidado em todas as instâncias da sociedade ${ }^{38}$.

Em alguns relatos do estudo de Belik \& Chaim $^{26}$, o conselho conseguiu barrar o processo de terceirização da alimentação escolar, exigir a contratação de nutricionista para atender ao programa e assegurar a participação dos conselheiros nos processos de licitação, chegando à conclusão de que o comprometimento dos membros do CAE tornou-se um fator fundamental para a articulação política e a conquista de benefícios ao programa. Verificou-se que foi determinante a atuação do conselho, sendo em diversos municípios encontradas melhorias na alimentação escolar, incentivo na participação dos pais e maior influência nas decisões da gestão pública ${ }^{26}$.

Conforme observado em investigação sobre os conselhos locais de saúde, ressalta-se que, para que os conselhos se tornem realmente valorizados, e ainda que a população esteja empoderada sobre a capacidade de realização do seu trabalho, deve existir uma consciência sobre a relevância da existência e atuação do conselho ${ }^{43}$.

Essa discussão é reforçada na presente pesquisa pela IC4: "Autonomia e eleição democrática do conselho, melhorias na alimentação escolar do município". Nela foi percebida a identificação de avanços na implantação dos conselhos de alimentação escolar entre alguns municípios participantes, em relação à maior transparência na eleição de seus representantes, às conquistas na efetivação da atuação do CAE, além do destaque das melhorias conquistadas na alimentação escolar, conforme já relatado por outros estudos ${ }^{7,38,40}$. Tais avanços estão identificados no DSC correspondente:

Autonomia do conselho para trabalhar, visitar, cobrar, participar das licitações, conhecer fornecedores, ver se não há desvio. Também há o comprometimento das pessoas que estão aqui, já que nós fomos realmente eleitos e isso foi um grande avanço. Nas escolas havia muita coisa errada, agora está melhorando cada vez mais. E, por fim, tem a questão da divulgação do nosso trabalho, já que o CAE saiu de dentro dos portões da secretaria (S.2cr; S.4cr; S.2fl).

No Discurso do Sujeito Coletivo também fica explícita a necessidade de expandir a atuação 
do CAE para além das secretarias de educação, divulgando o trabalho realizado pelo conselho em diferentes espaços. Verifica-se, portanto, que a existência de diálogo entre as estruturas institucionalizadas de controle social, entre espaços públicos e privados de organização social, impulsiona a ampliação da democracia e democratiza a existência dos conselhos com a publicização de ações $^{42,44}$.

\section{A visão do PNAE como uma política pública de Segurança Alimentar e Nutricional}

A análise das falas dos conselheiros investigados sobre a temática em apreço gerou a seguinte IC5: "O DHAA está inserido na legislação e todas as diretrizes do PNAE, e necessita ser consolidado não apenas no programa". O DSC derivado da IC 5 foi assim enunciado:

O DHAA é previsto na Constituição, como a garantia de todos terem uma alimentação igual e adequada. Contudo, este direito não atinge toda a população, mas o PNAE é uma iniciativa do Estado que busca garantir este direito na escola naquilo que é possível. No entanto, o governo precisa garantir esse direito de outras formas, com o salário e o emprego, por exemplo (S.2lg; S.2es; S.1es; S.2es; S.3sj; S.1sj; S.2sj; S.1bq).

Destaca-se, nesse discurso, a clareza de elementos que caracteriza o DHAA em sua totalidade, como o papel do PNAE na garantia do direito aos estudantes e também na responsabilidade do Estado para efetivação desse direito. Entretanto, a capacidade de o PNAE estimular o comércio local e a produção de alimentos, promover a sustentabilidade alimentar e a educação nutricional não foram citados como parte do universo da SAN, bem como do papel e também responsabilidade do controle social na consolidação do DHAA.

Gallina et al. ${ }^{25}$, em pesquisa sobre as representações de SAN dos conselheiros de alimentação escolar de um município do oeste catarinense, apontam o desconhecimento dos entrevistados sobre o conceito de SAN e a relação desse conceito com a política pública na qual estão inseridos, sendo identificadas representações limitadas e fragmentadas a respeito do tema, de forma semelhante ao presente estudo. Nesse sentido, ressalta-se que o conceito ampliado de SAN precisa ser comum a todos os atores envolvidos no PNAE, a fim de que as pautas e deliberações do conselho permeiem tal conceito.

Percebe-se ainda a necessidade de formação continuada dos conselheiros, desenvolvida pelos CECANE ${ }^{27}$ ou outras instâncias, porém essas formações precisam qualificar o CAE para a renovação dos conselhos e seus representantes, inserindo tanto o preparo conceitual como também o preparo político ${ }^{33}$. Nessa perspectiva, Morita et al. ${ }^{40}$ reforçam que, a partir do entendimento dos conselhos como espaços de desenvolvimento da democracia, eles devem ser estimulados à realização de formações, capacitando os conselheiros a respeito da política pública, suas funções e possibilidades de atuação.

Por fim, ressalta-se que o DHAA e a SAN no Brasil encontram-se em plena discussão no contexto das políticas públicas de alimentação e nutrição. Nesse sentido, o embasamento legal conquistado em 2006 com a promulgação da Lei Orgânica de Segurança Alimentar e Nutricional (Losan) ${ }^{45}$ e a incorporação, em 2010, do princípio do direito à alimentação na Constituição Federal do Brasil ${ }^{46}$ são instrumentos que garantem um suporte necessário para a promoção dessa discussão nos CAE, possibilitando que esses espaços tenham visibilidade e atuação pública rumo à efetivação desses direitos. Nessa mesma direção, a Política Nacional de Segurança Alimentar e Nutricional (Plansan), instituída no país em 2010, entre outras diretrizes, enfatiza o fortalecimento das ações de controle social, bem como a melhoria da execução do PNAE em todo o território nacional ${ }^{47}$. 


\section{CONCLUSÃO}

São reconhecidos os avanços das políticas públicas no Brasil nos últimos anos, incluindo a efetivação dos espaços de controle social, sobretudo na alimentação escolar. Dessa forma, o presente trabalho identificou que as funções do controle social no PNAE estão focadas no caráter fiscalizatório e no exercício de um papel burocrático e obrigatório dentro do programa, com pequenos avanços de intervenção na gestão pública pautados no comprometimento individual dos membros do CAE.

Em suma, emergiu dos discursos dos sujeitos investigados o entendimento do que é controle social e SAN, mas com a necessidade de maior divulgação desses temas entre a população. Emergiu ainda a ideia central de que esse espaço institucional - os CAE -, tem sua atuação limitada, uma vez que a autonomia, as verbas e a estrutura para a realização das suas ações são poucas ou inexistentes. Entretanto, reconheceram-se a melhoria da atuação e maiores intervenções na execução do PNAE quando os membros do CAE são comprometidos e recebem apoio da gestão pública (entidade executora).

Nesse sentido, torna-se fundamental a continuidade da capacitação dos conselheiros sobre os aspectos conceituais nas temáticas de SAN e DHAA e sua relação com a execução do PNAE. Reitera-se a necessidade de fortalecer a capacidade de articulação e negociação entre os atores envolvidos e a gestão do programa, além de outros espaços democráticos, com inclusão de discussão sobre cidadania e controle social nos espaços e currículos escolares. Tais premissas pressupõem o compromisso de transformação social, a luta por gestões públicas mais justas, o fortalecimento da democracia e, por consequência, a garantia do direito à alimentação escolar saudável, adequada e sustentável para todos os escolares brasileiros.

\section{COLABORADORES}

PMO MACHADO foi responsável pela análise de dados, elaboração e revisão do manuscrito. BAS
SCHMITZ deu apoio na análise de dados e revisão do manuscrito. ACT CORSO e GV CALDEIRA realizaram a coordenação do projeto e revisão do manuscrito. FAG VASCONCELOS teve participação no desenho, elaboração do projeto e revisão do manuscrito.

\section{REFERÊ NCIAS}

1. Brasil. Senado nacional. Secretaria Especial de Informática. Constituição da República Federativa do Brasil: texto promulgado em 5 de outubro de 1988. Brasília: Senado nacional; 2013 [acesso 2014 nov 8]. Disponível em: http://www.senado.gov.br/ legislacao/const/con1988/con1988_05.10.1988/ con1988.pdf

2. Carvalho Al. Conselhos de Saúde no Brasil: participação cidadã e controle social. Rio de Janeiro: Fase; 1995.

3. Cordeiro S, Cornwall A, Delgado NG. A luta pela participação e pelo controle social: o caso do Conselho Municipal de Saúde do Cabo de Santo Agostinho, Pernambuco. In: Romano J, Andrade MP, Antunes M. Olhar crítico sobre participação e cidadania: a construção de uma governança democrática e participativa a partir do local. São Paulo: Expressão Popular; 2007.

4. Assis MMA, Villa TCS. O controle social e a democratização da informação: um processo em construção. Rev Latino-Am Enfermagem. 2003; 11(3):376-82. http://dx.doi.org/10.1590/S0104-11 692003000300017

5. Kleba ME, Matielo A, Comerlatto D, Renk E, Colliselli L. O papel dos conselhos gestores de políticas públicas: um debate a partir das práticas em Conselhos Municipais de Chapecó (SC). Ciênc Saúde Coletiva. 2010; 15(3):793-802. http://dx.doi. org/10.1590/S1413-81232010000300022

6. Motta FCP, Alcadipani R. Jeitinho brasileiro, controle social e competição. Rev Adm Empres. 1999; 39(1):6-12. http://dx.doi.org/10.1590/S0034-75 901999000100002

7. Crubellate JM. Participação como controle social: uma crítica das estruturas organizacionais flexíveis. RAE. 2004; 3(2):1-18. http://dx.doi.org/10.1590/ S1676-56482004000200004

8. Brasil. Lei $n^{\circ} 8.913$, de 12 de julho de 1994. Dispõe sobre a municipalização da merenda escolar. 1994 [acesso 2014 nov 8]. Disponível em: http://www2. camara.leg.br/legin/fed/lei/1994/lei-8913-12-julho1994-349782-publicacaooriginal-1-pl.html

9. Peixinho AML. A trajetória do Programa Nacional de Alimentação Escolar no período de 2003-2010: relato do gestor nacional. Ciênc Saúde Colet. 2013; 18(4):909-16. http://dx.doi.org/10.1590/\$1413-8 1232013000400002 
10. Spinelli MAS, Canesqui AM. O programa de alimentação escolar no estado de Mato Grosso: da centralização à descentralização (1979-1995). Rev Nutr. 2002; 15(1):105-17. http://dx.doi.org/ 10.1590/S1415-52732002000100011

11. Brasil. Lei $n^{\circ} 11.947$, de 16 de julho de 2009. Dispõe sobre atendimento da alimentação escolar e do Programa Dinheiro Direto na Escola dos alunos da educação básica. Brasília: Ministério da Educação; 2009 [acesso 2012 dez 7]. Disponível em: http://www.fnde.gov.br/fnde/legislacao/leis/ item/3345-lei-n\%C2\%BA-11947-de-16-dejunhode-2009

12. Brasil. Ministério da Educação. Resolução CD/FNDE $n^{\circ} 38$, de 16 de julho de 2009. Dispõe sobre atendimento da alimentação escolar aos alunos da educação básica no Programa Nacional de Alimentação Escolar - PNAE. Brasília: Ministério da Educação; 2009 [acesso 2012 abr 12]. Disponível em: http://www.fnde.gov.br/arquivos/category/222009? download=57: res038-16 072009

13. Brasil. Ministério da Educação. Resolução CD/FNDE $n^{\circ} 26$, de 17 de junho de 2013. Dispõe sobre atendimento da alimentação escolar aos alunos da educação básica no âmbito do Programa Nacional de Alimentação Escolar - PNAE. Brasília: Ministério da Educação; 2013 [acesso 2014 jun 18]. Disponível em: http://www.fnde.gov.br/fnde/legislacao/ resolucoes/item/4620-resolu \% C3\%A7\%C3\% A3o-cd-fnde-n\%C2\%BA-26,-de-17-de-junho-de2013

14. Santos LMP, Santos SMC, Santana LAL, Henrique FCS, Mazza RPD, Santos LAS, et al. Avaliação de políticas públicas de segurança alimentar e combate à fome no período 1995-2002: 4 - Programa Nacional de Alimentação Escolar. Cad Saúde Pública. 2007; 23(11):2681-93. http://dx.doi.org/10.1590/S0 102-311X2007001100016

15. Anjos LA, Burlandy L. Construção do conhecimento e formulação de políticas públicas no Brasil na área de segurança alimentar. Ciênc Saúde Colet. 2010; 15(1):19-22. http://dx.doi.org/10.1590/S1413-81 232010000100003

16. Gabriel CG, Machado MS, Schmitz BAS, Corso ACT, Caldeiras GV, Vasconcelos FAG. Conselhos Municipais de Alimentação Escolar em Santa Catarina: caracterização e perfil de atuação. Ciênc Saúde Colet. 2013; 18(4):971-8. http://dx.doi.org/10.15 90/S1413-81232013000400009

17. Chaves LG, Santana TCM, Gabriel CG, Vasconcelos FAG. Reflexões sobre a atuação do nutricionista no Programa Nacional de Alimentação Escolar no Brasil. Ciênc Saúde Colet. 2013; 18(4):917-26. http:// dx.doi.org/10.1590/S1413-81232013000400003

18. Machado PMO, Machado MS, Schmitz BAS, Corso ACT, González-Chica DA, Vasconcelos FAG. Caracterização do Programa Nacional de Alimentação Escolar no Estado de Santa Catarina. Rev Nutr.
2013; 26(6):715-25. http://dx.doi.org/10.1590/s1 415-52732013000600010

19. Bandeira LM, Chagas CMS, Gubert MB, Toral N, Monteiro RA. Análise dos pareceres conclusivos dos Conselhos de Alimentação Escolar sobre a execução do Programa Nacional de Alimentação Escolar. Rev Nutr. 2013; 26(3):343-35. http://dx.doi.org/10.15 90/\$1415-52732013000300009

20. Siqueira RL, Cotta RMM, Ribeiro RCL, Sperandio N, Priore SE. Análise da incorporação da perspectiva do direito humano à alimentação adequada no desenho institucional do Programa Nacional de Alimentação Escolar. Ciênc Saúde Colet. 2014; 19(1):301-10. http://dx.doi.org/10.1590/1413-81 232014191.2114

21. Fernandes $A G S$, Fonseca $A B C$, Silva AA. Alimentação escolar como espaço para educação em saúde: percepção das merendeiras do município do Rio de Janeiro, Brasil. Ciênc Saúde Colet. 2014; 19(1):39-48. http://dx.doi.org/10.1590/1413-812 32014191.1711

22. Cunha DT, Gonçalves HVB, Lima AFA, Martins PA, Rosso VV, Stedefeldt E. Regional food dishes in the Brazilian National School Food Program: Acceptability and nutritional composition. Rev Nutr. 2014; 27(4):423-34. http://dx.doi.org/10.1590/14 15-52732014000400004

23. Silverio GA, Sousa AA. Organic foods from family farms in the National School Food Program: Perspectives of social actors from Santa Catarina, Brazil. Rev Nutr. 2014; 27(3):289-300. http://dx.doi. org/10.1590/1415-52732014000300003

24. Gomes NAA, Campos MRH, Monego ET. Aspectos higiênico-sanitários no processo produtivo dos alimentos em escolas públicas do Estado de Goiás, Brasil. Rev Nutr. 2012; 25(4):473-85. http://dx.doi. org/10.1590/S1415-52732012000400005

25. Gallina LSA, Teo CRPA, Munaro PS, Oliveira VSH. Representações sobre segurança alimentar e nutricional nos discursos de um Conselho de Alimentação Escolar. Saúde Soc. 2012; 21(1):89-102. http://dx.doi.org/10.1590/S0104-129020120001 00010

26. Belik W, Chaim NA. O Programa Nacional De Alimentação Escolar e a gestão municipal: eficiência administrativa, controle social e desenvolvimento local. Rev Nutr. 2009; 22(5):595-607. http://dx.doi. org/10.1590/S1415-52732009000500001

27. Scarparo AL, Moulin CC, Ruiz EF, Schuch I, Araújo JS, Souza M, et al. Ações do Centro Colaborador em Alimentação e Nutrição do Escolar da Universidade Federal do Rio Grande do Sul. Clin Biomed Res. 2010 [acesso 2012 abr 2]; 30(3):302-5. Disponível em: http://seer.ufrgs.br/hcpa/article/view/ 16211

28. Minayo MC. Pesquisa social: teoria, método e criatividade. $18^{\mathrm{a}}$ ed. Petrópolis: Vozes; 2001. 
29. Minayo MC. O desafio do conhecimento: pesquisa qualitativa em saúde. $11^{\text {a }}$ ed. São Paulo: Hucitec; 2008.

30. Gomes VLO, Telles KS, Roballo EC. Grupo focal e discurso do sujeito coletivo: produção de conhecimento em saúde de adolescentes. Esc Anna Nery. 2009; 13(4):856-62. http://dx.doi.org/10.1590/s1 414-81452009000400023

31. Ressel LB, Beck CLC, Gualda DMR, Hoffmann IC, Silva RM, Sehnem GD. O uso do grupo focal em pesquisa qualitativa. Texto Contexto Enferm. 2008; 17(4):779-86. http://dx.doi.org/10.1590/\$0104-07 072008000400021

32. Lefevre F, Lefevre AMC. Pesquisa qualitativa levada a sério [acesso $2012 \mathrm{abr}$ 1]. Disponível em: http:// www.fsp.usp.br/ flefevre/Discurso_o_que_e.htm

33. Lefevre $F$, Lefevre AMC. O sujeito coletivo que fala. Interface. 2006; 10(20):517-24. http://dx.doi.org/ 10.1590/S1414-32832006000200017

34. Lefevre F, Lefevre AMC. O discurso do sujeito coletivo e o Qualiquantisoft [apresentação]. 2007 [acesso 2012 jan 15]. Disponível em: http://www. ipdsc.com.br/scp

35. Gerschman S. Conselhos Municipais de Saúde: atuação e representação das comunidades populares. Cad Saúde Pública. 2004; 20(6):1670-81. http://dx.doi.org/10.1590/S0102-311X20040 00600026

36. Cotta RMM, Cazal MM, Rodrigues JFC. Participação, controle social e exercício da cidadania: a (des)informação como obstáculo à atuação dos conselheiros de saúde. Physis. 2009; 19(2):419-38. http://dx.doi.org/10.1590/S0103-733120090 00200010

37. Badue AFB, Chmielewska D, Instututo Kairós. Controle social na alimentação escolar. São Paulo: O Instituto; 2011 [acesso 2013 fev 12]. Série Caminhos para práticas de consumo Responsável, $n^{\circ}$ 3. Disponível em: http://www.mda.gov.br/portal/ arquivos/view/KAIROS_Controle_Social_na_ Alimentacao_Escolar.pdf

38. Pipitone MAP, Ometto AMH, Silva MV, Sturion GL, Furtuoso MCO, Oetterer M. Atuação dos conselhos municipais de alimentação escolar na gestão do Programa Nacional de Alimentação Escolar. Rev Nutr. 2003; 16(2):143-54. http://dx.doi.org/10.15 90/S1415-52732003000200001

39. Alvarez MC. Controle social: notas em torno de uma noção polêmica. São Paulo Perspec. 2004; 18(1):168-76. http://dx.doi.org/10.1590/S010288392004000100020

40. Morita I, Guimaraes JFC, Di Muzio BP. A participação de Conselheiros Municipais de Saúde: solução que se transformou em problema? Saúde Soc. 2006; 15(1):49-57. http://dx.doi.org/10.1590/S0104-1 2902006000100006
41. Rodriguez V. Financiamento da educação e políticas públicas: o Fundef e a política de descentralização. Cad CEDES. 2001; 21(55):42-57. http://dx.doi.org/ 10.1590/S0101-32622001000300004

42. Bispo JJP, Gerschman S. Potencial participativo e função deliberativa: um debate sobre a ampliação da democracia por meio dos conselhos de saúde. Ciênc Saúde Colet. 2013; 18(1):7-16. http://dx. doi.org/10.1590/S1413-81232013000100002

43. Shimizu HE, Pereira MF. A burocratização das práticas cotidianas dos conselhos de saúde: como superar? Tempus: Actas Saúde Colet. 2009 [acesso 2012 dez 12]; 3(3):56-66. Disponível em: http:// www.tempusactas.unb.br/index.php/tempus/ article/download/722/731

44. Santos MRM. Conselhos municipais e a participação cívica na gestão das políticas públicas: o caso da metrópole uminense. Cad Metrop. 2002 [acesso 2013 mai 5]; 7(1):97-112. Disponível em: http:// revistas.pucsp.br/index.php/metropole/article/view/ 9261/6871

45. Brasil. Lei $n^{\circ} 11.346$, de 15 de setembro de 2006. Cria o Sistema Nacional de Segurança Alimentar e Nutricional - SISAN com vista a assegurar o direito humano à alimentação adequada e dá outras providências. Diário Oficial da União. 2006; 18 set, p.1, Seção 1 [acesso 2012 dez 7]. Disponível em: http://www2.camara.leg.br/legin/fed/lei/2006/lei11346-15-setembro-2006-545529-publicacao original-58455-pl.html

46. Brasil. Emenda Constitucional $n^{\circ} 64$, de 4 de fevereiro de 2010. Altera o art. $6^{\circ}$ da Constituição Federal para introduzir a alimentação como direito social. Diário Oficial da União. 2010; 5 fev, p.1-2, Seção 1 [acesso 2012 dez 7]. Disponível em: http:// www.planalto.gov.br/ccivil_03/constituicao/ Emendas/Emc/emc64.htm

47. Brasil. Decreto $n^{\circ} 7.272$, de 25 de agosto de 2010. Regulamenta a Lei $n^{\circ} 11.346$, de 15 de setembro de 2006, que cria o Sistema Nacional de Segurança Alimentar e Nutricional - SISAN com vistas a assegurar o direito humano à alimentação adequada, institui a Política Nacional de Segurança Alimentar e Nutricional - PNSAN, estabelece os parâmetros para a elaboração do Plano Nacional de Segurança Alimentar e Nutricional, e dá outras providências. Diário Oficial da União. 2010; 26 ago, p.6, Seção 1 [acesso 2014 jul 12]. Disponível em: http://www 2.camara.leg.br/legin/fed/decret/2010/decreto7272-25-agosto-2010-608094-publicacaooriginal129056-pe.html

Recebido: julho 3, 2013 Versão final: novembro 28, 2014 Aprovado: março 12, 2015 
